\title{
Imágenes y palabras en la lucha por imposición de sentidos: la imagen como generadora de relatos
}

\section{Ruiz, Santiago; Triquell, Ximena}

Resumen:

Es conocido el recorrido que Philippe

Dubois propone sobre la segunda tricotomía peirceana -ícono, índice y símbolo- para analizar las posiciones que históricamente se han establecido entre la fotografía y lo "real": la imagen ícono ("espejo" del mundo); la imagen símbolo (sujeta a convenciones); la imagen índice (huella de lo real).

Resulta evidente que esta sucesión no propone una evolución, sino más bien posibles lecturas del signo visual.

Como consecuencia de esto, ícono, índice y símbolo, lejos de referir a una tipología, constituyen formas de funcionamiento -lecturas- de éstos. No obstante, un hecho insoslayable es que, desde el punto de vista de la

\section{Cuadernos del Centro de Estudios de} Diseño y Comunicación № 61

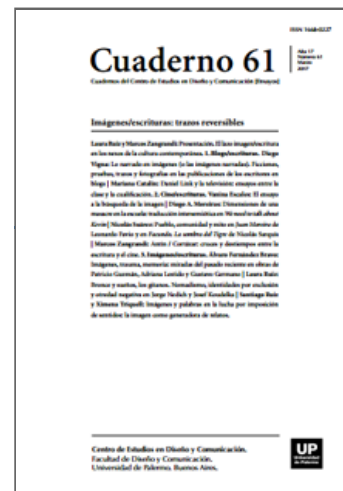

ISSN: 1668-0227

Imágenes/escrituras:

trazos reversibles

Año XVII, Marzo 2017, Buenos Aires, Argentina | 176 páginas

descargar PDF

ver índice de la publicación

Ver todos los libros de la publicación

compartir en Facebook

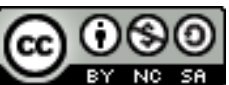

Esta obra está bajo una Licencia Creative Commons Atribución-NoComercialCompartirlgual 4.0 Internacional

recepción, las imágenes proponen una relación menos mediatizada que lo lingüístico con un supuesto referente "real" y por lo tanto - esta es nuestra hipótesis- poseen una mayor eficacia en la lucha por la imposición de sentidos.

Así, si los discursos en general "construyen la realidad", las representaciones visuales asumen dentro de éstos una eficacia particular en tanto se nos imponen con la fuerza de la evidencia, de lo que está allí (la copia exacta y/o la huella de lo real).

Palabras clave: imágenes - signos lingüísticos - signos visuales - semiótica visual.

${ }^{*}$ ) Profesor en Letras Modernas y Magister en Sociosemiótica por la Universidad Nacional de Córdoba. Profesor Adjunto en la materia Lingüística y Profesor Asistente en la asignatura Semiótica de la Escuela de Ciencias de la Información de la UNC. Dirige junto a Ximena Triquell el proyecto de investigación "Imágenes del conflicto: Construcciones visuales de la conflictividad social en la Argentina contemporánea". 
$\left.{ }^{(* *}\right)$ Magister y Doctora en Teoría Crítica por la Universidad de Nottingham, Inglaterra, y Licenciada y Profesora en Letras por la Universidad Nacional de Córdoba. Profesora Titular de la Cátedra Cine y Narrativa en el Departamento de Cine y Tv de la Facultad de Artes y Profesora Adjunta de Semiótica en la carrera de Letras de la Facultad de Filosofía y Humanidades de la UNC. Es investigadora asistente de CONICET y coordina el Grupo de Estudios de la Imagen de la Universidad Nacional de Córdoba.

La lucha por la imposición de sentido

Este texto parte de una suposición y una pregunta. La primera refiere a una concepción de lo social como campo de lucha por la imposición de sentidos. Esta presuposición, puramente semiótica, define los límites pero también las potencialidades de nuestra reflexión.

De los múltiples aspectos en que se puede pensar lo social, nosotros elegimos hacerlo desde lo discursivo, esto es, desde aquella dimensión que considera que los discursos no son sólo lo "que traduce las luchas o los sistemas de dominación, sino aquello por lo que, y por medio de lo cual se lucha, aquel poder del que quiere uno adueñarse", al decir de Michel Foucault (1987, p. 12).

En efecto, si tras lo que se conoce como el giro lingüístico ya no nos es dado pensar una relación de transparencia, de tranquila correspondencia entre los signos y las cosas, que nos otorgara la tranquilidad de sabernos en "la verdad" por la sola adecuación entre ambas dimensiones, por la mera "correlación" entre discurso y mundo, se vuelve fundamental pensar en los mecanismos a través de los cuales se establece tal relación. ¿Quién y cómo define lo que los signos significan? Esta será la verdadera lucha en el campo de lo social.

Pero si ya no podemos sostener un vínculo "natural" entre las cosas del mundo y los signos a los que recurrimos para nombrarlas, a la vez que continuamos reconociendo este vínculo (en la medida en que recurrimos a palabras para referir al mundo), la relación debe analizarse en la propia dinámica de lo social. Para Ferdinand de Saussure, será a través de la convención social, vivida como norma, como se fijen los sentidos; para Charles Sanders Peirce debe hacerse en el desarrollo de la semiosis, la red de signos en las que los propios sujetos se constituyen a sí mismos y constituyen la realidad como realidad significada.

De este modo, lejos de la ilusión de una realidad prístina a la que señalar y explicar con nuestros lenguajes (verbal o visual), necesitamos admitir una "masa amorfa" -como quería Saussure- de pensamiento y sonidos que articulamos, para construir, a través de ellos, los conceptos que nos permiten descansar en la presunta comprensión del mundo. $\mathrm{O}$, desde la perspectiva peirceana, esa pura primeridad caótica e indeterminada, que nuestro pensamiento organiza de manera siempre provisoria, siempre inacabada, para poder operar sobre el mundo.

Ahora bien, si somos los seres humanos con nuestros lenguajes los que construimos y damos forma a lo real, este hacer no está -como ninguna actividad humana- exento de poder.

Toda producción de sentido (en palabras o imágenes) tiene como resultado la puesta en circulación de determinadas "representaciones" las que, lejos de "reflejar la realidad", la construyen, siempre de determinada manera, siempre a ciertos efectos; o lo que es lo mismo, siempre en cruce con lo ideológico y el poder. 
En este marco, la pregunta que nos hacemos es sobre aquello que diferencia a las palabras de las imágenes en esta lucha por la imposición de sentidos. ¿Qué las separa? ¿Qué las acerca? ¿Qué relación guardan con la forma en que ponemos a circular sentidos en nuestras sociedades cada vez más mediatizadas, cada vez más sociedades "de la imagen"?

Íconos, índices, símbolos

Como se recordará, el número tres es la clave en la teoría peirceana, ya sea que se refiera a su particular fenomenología (la faneroscopía), a su concepción triádica del signo o a su clasificación de los signos (o modos de significar, en una lectura más precisa).

En el primer caso, haciendo un análisis (lógico) de "lo que aparece en el mundo", clasifica al ser -"tanto las ideas como las cosas, e ideas que imaginamos tener, así como ideas que realmente tenemos"- en tres órdenes: primeridad (el modo de ser de lo que es sin tener en cuenta cualquier otra cosa); segundidad (el modo de ser de lo que es en relación a otra cosa, pero excluyendo cualquier tercero); terceridad (el modo de ser de aquello que relaciona un primero y un segundo) (Peirce, 1987, pp. 110-111). La primeridad comporta las ideas de vaguedad, generalidad, indeterminación, variedad ilimitada, cualidad del sentimiento. La segundidad es del orden de lo existente, lo concreto, el hecho bruto, la reacción puramente opositiva entre dos existentes; al dar cuenta de la existencia, de lo que aparece a los sentidos, este es el orden de la realidad bruta. La terceridad es el reino de la mediación, de la relación, de la ley, la regularidad y el hábito, en la medida en que siempre debe haber un criterio a partir del cual se pongan en relación dos elementos (cf. Peirce, 1931, pp. 148-229).

Si trasladamos este desarrollo a la concepción del signo, nos remitimos -de entre los múltiples intentos de definición que Peirce planteó a lo largo de sus escritos- a la siguiente definición: Un signo o representamen es un primero que está en una relación triádica genuina tal con un segundo, llamado su objeto, que es capaz de determinar un tercero, llamado su interpretante, para que asuma la misma relación triádica con su objeto que aquella en la que se encuentra él mismo respecto del mismo objeto.

(Peirce, 1932, p. 156) Es decir: representamen, objeto e interpretante, los tres elementos de la relación triádica llamada "signo", también son entendidos desde una perspectiva faneroscópica como un indeterminado que se relaciona con un objeto de la realidad, relación juzgada por una ley que la establece.

Ahora bien, aplicando las tríadas a una clasificación de los signos, es posible distinguir tres tricotomías según cómo el signo o representamen se presenta a sí mismo (primeridad), cómo se relaciona con su propio objeto (segundidad), o cómo se relaciona con su interpretante (terceridad). De estas tres tricotomías, la más desarrollada por el propio autor -y también la que más productiva ha resultado ser en el análisis semiótico, sea cual sea la materialidad del objeto analizado (texto lingüístico, imagen fija, audiovisual, etc.)- es la segunda, justamente porque permite dar cuenta de la manera en que el signo representa lo que representa, plantea su forma de estar en lugar de su objeto; en definitiva, de la manera en que el signo muestra su relación con el "hecho real".

Según esta, el signo puede ser entendido como un ícono, un índice o un símbolo. Un signo-ícono se relaciona con su objeto a partir de ser "una imagen inmediata", es decir por una analogía en la apariencia con el objeto que representa: Es un representamen de lo que representa y para la mente que lo interpreta como tal, en virtud 
de que es una imagen inmediata, es decir, en virtud de los caracteres que le pertenecen como un objeto sensible, y que poseería del mismísimo modo aun si no hubiese en la naturaleza un objeto que se le pareciera, y aunque nunca se lo interpretara como un signo. Tiene la naturaleza de una apariencia y, como tal, en términos estrictos, sólo existe en la conciencia.

(Peirce, 1987, p. 360) El criterio de definición del ícono reside en que es análogo, semejante al objeto que representa, ya sea que éste sea existente -en ese sentido, se entiende que una fotografía instantánea es un ícono-, sea ficticio -por ejemplo, el diseño dibujado o digitalizado de un unicornio o de un centauro-, o puramente mental, como un diagrama geométrico.

Si el ícono representa objetos que bien pueden existir o ser puramente imaginarios, el índice solo puede dar cuenta de lo que existe ciertamente en nuestra realidad. En ese sentido, Peirce presenta estos dos tipos como naturalmente opuestos. Un índice es: Una cosa o un hecho real que es un signo de su objeto en virtud de estar conectado con éste como algo obvio. (...) Puede servir simplemente para identificar su objeto y asegurarnos de su existencia y presencia. (...) da pruebas a partir de las cuales se puede extraer una seguridad positiva en cuanto a la verdad del hecho.

(Peirce, 1987, p. 361) El índice se relaciona con su objeto a partir de una conexión fáctica, existencial; al ser "una cosa o hecho real", debe compartir el mismo espacio con el objeto que representa, y por ello son ejemplos de índice también la fotografía, una flecha indicando una dirección determinada o una sirena de ambulancia, entre otros.

El criterio por el cual un símbolo se relaciona con su objeto está determinado por la convención, la ley, un hábito preestablecido: "un símbolo es un representamen cuyo significado o aptitud especial para representar justamente lo que representa sólo reside en el hecho de que hay un hábito, una disposición u otra regla general eficaz de que así se lo interpretará" (Peirce, 198, p. 361).

Aunque la segunda tricotomía de Peirce es, como dijimos, muy conocida, detengámonos en un ejemplo para ilustrarla.

En este caso, reconocemos en la figura representada (Imagen 1), cualidades -características propias- del personaje histórico de Eva Perón y por ello, leemos la imagen como ícono. Este signo no nos brinda prueba de existencia del objeto, ya que la imagen pudo ser dibujada sin necesidad de que existiera el personaje histórico pero sí nos informa sobre ciertas cualidades del mismo.

Por el contrario, en esta segunda imagen (Imagen 2), no sólo reconocemos al personaje histórico (por lo cual la consideramos también un ícono) sino que atribuimos al hecho histórico al que refiere valor de verdad, ya que se trata de una fotografía y sabemos que ésta requiere de un existente que deje su huella al pasar la luz por el lente e imprimirse sobre el papel fotosensible; en otras palabras signo y objeto están unidos por una "conexión existencial". De esta relación proviene el poder atestiguador del índice que, como veremos, ha sido considerado su principal valor.

Finalmente, en esta última imagen (Imagen 3) reconocemos a través de una serie de convenciones -referidas a la representación de Eva Perón pero también al lenguaje audiovisual, la producción cinematográfica, al star 
system hollywoodense, etcétera- a Madonna actuando en el rol de Eva Perón. Se trata de un símbolo, evidentemente, pero que se sostiene sobre el índice del registro fotográfico (el índice de Madonna) y sobre el ícono de la imagen anterior (Eva Perón en el acto del 22 de agosto de 1951).

No obstante, como se deduce de lo anterior, ícono, índice y símbolo no refieren a categorías fijas, sino más bien a formas de funcionamiento de los signos (un mismo signo puede ser ícono, índice y símbolo a la vez) o a formas de lectura de estos (un mismo signo puede ser leído como ícono, índice o símbolo según el contexto).

Imágenes y palabras

En función de lo anterior, podemos decir que, en términos muy generales, las palabras son predominantemente símbolos; esto es, su significación se sostiene en una convención.

Esta característica es la que lleva a Saussure a considerar a los signos lingüísticos, los más "acabados", en tanto están definidos principalmente por la arbitrariedad. Es cierto que también en el ámbito de la lengua encontramos íconos, como las onomatopeyas, e índices, como los deícticos, pero estas funciones están subsumidas a la relación convencional que define al símbolo, como ya había observado el mismo Saussure.

Por el contrario, cuando nos enfrentamos a imágenes encontramos múltiples posibilidades de lecturas. Philippe Dubois recurre a la tricotomía peirceana para analizar las diferentes posiciones que históricamente se han establecido entre la fotografía y lo "real": la imagen ícono (esto es la imagen como "espejo", reflejo del mundo); la imagen símbolo (la imagen inevitablemente sujeta a convenciones); la imagen índice (la imagen como huella de una realidad, de la cual depende). Si bien Dubois se concentra sobre la imagen fotográfica, su teorización puede ser extendida a las imágenes en general (cf. Dalmasso, 1994).

Son también conocidas las diversas posiciones de algunos teóricos en relación a estas posibilidades.

Podemos recuperar en la primera de estas lecturas la propuesta temprana de Roland Barthes cuando se refiere a las imágenes como "un mensaje sin código" o el "analogon perfecto" de la realidad. En "Retórica de la imagen", recordamos, hablando del nivel literal de la famosa fotografía de la publicidad de Panzani, afirma: "el signo de este mensaje no proviene de un depósito institucional, no está codificado, y nos encontramos así frente a la paradoja (...) de un mensaje sin código". Esto implica que, para entender este signo, no necesitamos otro saber más que el de nuestra propia percepción, un saber "casi antropológico" en la medida en que conociendo cuáles son los objetos fotografiados en la realidad se establece correctamente la relación, sin necesidad de recurrir a ningún tipo de código o convención preestablecida. Barthes llamó a este nivel de lectura de la imagen "mensaje icónico no codificado" (1974, p. 130).

En otro artículo del mismo volumen de Communications, "El mensaje fotográfico", Barthes refuerza esta idea: "Si bien es cierto que la imagen no es lo real, es por lo menos su analogon perfecto, y es, precisamente, esa perfección analógica lo que, para el sentido común, define la fotografía" (1974, p. 116). Obviamente, Barthes plantea esta cuestión atendiendo a una lectura inmediata de la imagen fotográfica, que deja de lado los "mensajes suplementarios" que dan cuenta de un determinado estilo, un determinado tratamiento de la imagen, estos sí mediados por ciertos saberes culturales ya codificados. 
Sin desatender al carácter icónico de la imagen, Umberto Eco hace ingresar de lleno, en "Semiología de los mensajes visuales", el carácter codificado de la percepción de los signos icónicos. Según expone, estos "reproducen algunas condiciones de la percepción del objeto, pero después de haberlas seleccionado según códigos de reconocimiento y haberlas registrado según convenciones gráficas" (Eco, 1982, p. 30). Eco desarrolla de manera exhaustiva en el mismo artículo la multiplicidad de códigos (perceptivos, de reconocimiento, de transmisión, icónicos, iconográficos...) que intervienen en la lectura de una imagen, a fin de señalar una cierta primacía de lo simbólico sobre lo icónico (cf. Eco, 1982, p. 61 ss.).

Finalmente, entender la imagen como índice refiere, en gran medida, al momento de producción del signo fotográfico (su génesis, el arché en términos de Schaeffer), a partir del cual se yergue en huella del objeto representado, pero también y por lo mismo -desde una perspectiva pragmática- en su capacidad de constituirse como prueba de verdad, de atestiguamiento, por un lado, y en su potencialidad para imponerse a nuestra percepción, por otro (cf. Dubois, 1986, y Dalmasso, 1994, p. 43 ss.).

Si nos atenemos a esta última lectura, debemos recuperar que el índice, al definirse a partir de una relación de contigüidad con su objeto, al ser un signo de la segundidad, "una cosa o un hecho real que es un signo de su objeto en virtud de estar conectado con éste como algo obvio" (Peirce, 1987, p. 361), se convierte en el único de los tipos de signos que da - justamente por esta "conexión fáctica"- seguridad de la "existencia y presencia" del objeto en cuestión, de allí que la indicialidad funcione como garantía de existencia.

No obstante, un rasgo del índice, no suficientemente considerado, es que también se trata de un signo de reacción, de choque con lo real, de allí su capacidad de llamar la atención, de entrometerse, de irrumpir en nuestra percepción. El índice no puede ser "evitado" en su aparición; se nos impone como un golpe a nuestros sentidos: los índices "dirigen la atención hacia sus objetos mediante una ciega compulsión" dice Peirce (1987, p. 276). Los ejemplos a los que recurre en distintos pasajes de su obra dan cuenta de esta evidencia: Un golpe en la puerta es un índice. Cualquier cosa que concentra la atención es un índice. Cualquier cosa que nos sobresalta es un índice, en la medida en que marca la conjunción entre dos porciones de la experiencia.

(...) Cuando un conductor que quiere atraer la atención de un peatón y lograr que se salve le grita: “¡Eh!”, (...) en la medida en que está simplemente dirigida a actuar sobre el sistema nervioso del oyente y a impulsarlo para que salga del camino, es un índice... (Peirce, 1987, pp. 266-267) Hay entonces una particular relación del índice con la realidad, que consiste en esa capacidad del signo de presentarla ante nuestras narices, obligándonos a percibirla, dirigiendo nuestra percepción (visual, auditiva, etcétera) hacia donde nos indica.

Es en este aspecto donde radica para nosotros la potencialidad diferencial de las imágenes en el marco de la lucha por la imposición de sentidos a la que nos referíamos arriba. Esto es: si bien en un determinado nivel las imágenes participan de lo simbólico al igual que claramente lo hacen las palabras, ya sea en la oralidad como en el texto escrito, desde el punto de vista de la recepción, desde su reconocimiento o efectos - diría Verón (1996)las imágenes proponen una relación menos mediatizada que lo lingüístico con un supuesto referente "real" y, por lo tanto, se nos imponen con una fuerza particular. 
A partir de lo anterior, podemos entonces entender las palabras ligadas a lo simbólico, y las imágenes asociadas a lo indicial y a lo icónico. Pero hay una situación en la cual se produce un cruce entre estos dos regímenes: la escritura.

Considerada por algunos autores como un simple sistema secundario de representación de la lengua hablada (Saussure, Lotman), la escritura es más que eso, implica una forma particular de organizar el pensamiento y amplía las posibilidades de la oralidad a límites impensados por culturas que no la conocían (Ong, 1982, pp. 1719). Siendo un invento, situada su aparición en un momento más o menos preciso de la historia de la humanidad, un artificio, una tecnología que requiere no solo de un aprendizaje particular sino también de elementos extraños al cuerpo humano (ya sea para la inscripción como en relación al soporte sobre el cual realizarla), la escritura se opone en el eje artificial / natural al lenguaje hablado, capacidad específica del ser humano, para la cual ya está genéticamente dotado y la cual desarrolla sin grandes complicaciones en los primeros años de su vida.

Hasta tiempos relativamente recientes -si se la compara con la oralidad- la escritura fue un trabajo reservado solo para quienes se habían especializado en ella e, incluso, antes de su popularización el trabajo de la escritura alfabética era lento y se acercaba a la pintura; incluso mantiene algunos de esos rasgos en escrituras actuales, como es el caso de los logogramas chinos.

El cuidado en el trazado de los grafos en sus orígenes acerca la tarea del escriba a la del artista. No quiere decir esto que su valor simbólico desaparezca sino que a éste se agrega un valor estético que descansa sobre lo icónico. Este valor estético, que se reconoce desde los escribas antiguos y, sobre todo, medievales a los actuales diseñadores al elegir una fuente determinada, ha sido utilizado y explotado por numerosos poetas y artistas, desde los caligramas de Guillaume Apollinaire y de Vicente Huidobro y las parole in libertà de Filippo Marinetti, hasta el agregado de textos escritos en los cuadros de René Magritte, Raoul Hausmann y otros plásticos vanguardistas.

Pero si la distinción entre palabras e imágenes encuentra en la escritura su cruce en relación a lo icónico, aún persiste la pregunta acerca de la diferencia en la especificidad de las segundas para imponer sentidos.

\section{La imagen generadora de relatos}

En sus primeras reflexiones semiológicas, Roland Barthes afirmaba que las imágenes están, tarde o temprano, destinadas a encontrarse con el lenguaje escrito, ya sea como anclaje o complemento en la función que denomina relevo (idea que campea también los artículos aludidos arriba). En el primer caso, la imagen, debido a su necesaria polisemia, requiere del lenguaje escrito para anclar los sentidos y evitar la dispersión en direcciones no deseadas por su autor; en el segundo, textos escritos e imágenes se complementan y encuentran su unidad en un nivel superior, como por ejemplo el de la narratividad, como sucede en las historietas.

Ahora bien, Barthes partía del principio de que la polisemia de la imagen requería ser reducida: el anclaje opera en este sentido al recortar y destacar, entre todas las potencialidades interpretativas que plantea la imagen, aquella que debe imponerse sobre las demás en el momento de la recepción, limitando, recortando, entre múltiples posibilidades, una. 
Para Barthes, la imagen propone un exceso. Por el contrario, desde nuestra perspectiva es necesario reformular este principio y asumir que la imagen más que polisémica aparece en su materialidad vacía de sentido, esto es: tanto en su indicialidad como en su iconicidad la imagen sólo muestra, no puede narrar, ni argumentar. De allí que las bajadas de las fotografías que Barthes consideraba anclajes resulten más bien relatos en los cuales enmarcar el instante que la fotografía muestra, describe.

Esta condición de la imagen nos lleva a recuperar uno de los rasgos de la indicialidad que desarrollamos arriba. Como todo signo-índice, la imagen se entromete en nuestra percepción y nos muestra algo, ostenta. Casi como Alex De Large sufriendo su reeducación en La naranja mecánica (A clockwork orange, dirigida por Stanley Kubrick, 1971), nos vemos obligados a percibirla, a no apartar nuestra vista de lo que nos muestra. El poder específico de las imágenes no radica -o no solamente- en su supuesta capacidad de "dar cuenta de" sino en su intromisión en nuestra conciencia de manera abrupta y necesaria, en esa potencialidad propia del índice.

Pero la imagen, siendo ella quien se nos impone, no nos obliga a leerla en un sentido determinado, la imagen simplemente exhibe, nos dice "esto es" o "esto ha sido", y nada más. Con eso solo si bien hay sentido, no hay relato ni argumentación, solo ostensión y por ende, no hay discurso (si consideramos que narrar y argumentar son las dos grandes formas de puesta en discurso). De allí que en relación a la fotografía esta discusión se haya centrado en la prueba de existencia, el atestiguamiento, el "esto ha sido" (Barthes, 1989). Como un signo aislado, la fotografía remite a un objeto pero no nos dice nada más sobre éste. Ante ella sólo podemos describir lo que muestra.

No obstante, junto a -o debido a- esta limitación surge la principal potencialidad que diferencia a las imágenes de otras materialidades significantes: la capacidad de "hacernos hablar", es decir de obligarnos a generar relatos para entenderlas. En efecto, es armando relatos -como efecto propio de una imagen- que podemos nosotros plantear "sentido" a partir de una imagen; ese sentido que no es propio de ella, sino que es atribuido en reconocimiento.

En 1840, en los orígenes de las fotografía, Hypolitte Bayard intuyó esto, y se retrató a sí mismo en la figura de un muerto como reclamo al gobierno francés por el escaso reconocimiento que le había dado frente al brindado a su competidor, Louis Daguerre, cuyo invento, el daguerrotipo, había reconocido y a quien había dotado con honores y una pensión vitalicia.

Esta imagen muestra a un hombre semidesnudo, envuelto en una suerte de túnica, recostado con los ojos cerrados (Imagen 4). Nada nos dice de su identidad, ni del motivo de su gesto. Mucho menos, si acaso llegamos a deducir que se trata de un muerto, de los motivos que llevaron a esa muerte. Bayard sabe esto y por eso agrega, en el reverso de una de las tres imágenes que realiza con este motivo, un texto que explica cómo debe ser leída la fotografía (Imagen 5).

Este cadáver que ven ustedes es el del Señor Bayard, inventor del procedimiento que acaban ustedes de presenciar, o cuyos maravillosos resultados pronto presenciarán. Según mis conocimientos, este ingenioso e infatigable investigador ha trabajado durante unos tres años para perfeccionar su invención.

La Academia, el Rey y todos aquellos que han visto sus imágenes, que él mismo consideraba imperfectas, las han admirado como ustedes lo hacen en este momento. Esto le ha supuesto un gran honor, pero no le ha 
rendido ni un céntimo. El gobierno, que dio demasiado al Señor Daguerre, declaró que nada podía hacer por el Señor Bayard y el desdichado decidió ahogarse.

¡Oh veleidad de los asuntos humanos! Artistas, académicos y periodistas le prestaron atención durante mucho tiempo, pero ahora permanece en la morgue desde hace varios días y nadie le ha reconocido ni reclamado. Damas y caballeros, mejor será que pasen ustedes de largo por temor a ofender su sentido del olfato, pues, como pueden observar, el rostro y las manos del caballero empiezan a descomponerse. H. B. 18 de octubre de 1840. (cit. en Batchen, 2004, p. 172) Geofrey Batchen (2004) analiza esta y las otras fotografías de la serie: observa las imágenes, menciona las mínimas variaciones entre una y otra, estudia en detalle la composición, la pose del hombre fotografiado, señala las relaciones con otras fotografías de Bayard y con la tradición pictórica y escultórica, incluso relaciona ciertas opciones con hechos históricos contemporáneos, pero nada puede decir de lo representado. Nada, hasta que considera el reverso de la foto. Aquí encuentra, en sus palabras, "la historia completa, o al menos, el guión íntegro".

Y es que la imagen por sí sola no puede contarnos nada ni del mundo ni de sí; sólo puede señalar hacia ese mundo al señalarse a sí misma: "He aquí un hombre, recostado semidesnudo, con los ojos cerrados". Pero este señalamiento es ya una incitación no a la lectura de un guión previo que estaría inscripto de una vez y para siempre en la imagen sino a su construcción. La imagen nos hace hablar, nos moviliza, nos obliga, a construir relatos.

Tomando distancia del poder documental/testimonial de la fotografía, Bayard pone en juego esta posibilidad, tan temprano como el mismo surgimiento del dispositivo: Bayard posa como un objeto cadáver/escultura/cuadro/naturaleza muerta- para convertirse en sujeto merecedor de atención y reconocimiento por nuestra parte (y por parte del Estado). Ni por asomo intenta presentar la fotografía como una analogía de la "vida real"; en realidad, es todo lo contrario (aquí no hay nada más que representación y representaciones de representaciones").

(Batchen, 2004, p. 173) Así, del reconocimiento de la existencia de una forma, un objeto, una apariencia, de la atestiguación de algún elemento de "la realidad", al establecimiento de un discurso, la imagen media como generadora de relatos, de relatos explicativos, narrativos, argumentativos, que surgen gracias a aquella, que (podríamos aventurarnos) emanan de ella pero que no están en ella.

Su fuerte presencia material, su pesadez y su intromisión conforman un núcleo duro de generación de discursos, ponen ineludiblemente en marcha la máquina interpretativa.

Más que en atestiguar una realidad, su poder consiste en habilitar la producción de relatos sobre esa "realidad", en movilizar creencias que guiarán acciones, en poner a circular sentidos que se enfrentan, se apoyan, se responden, se critican. Pero la imagen no solo habilita la producción de relatos, sino que también, en un movimiento inverso al planteado por Barthes con la función de anclaje del mensaje lingüístico respecto del icónico, es ella misma la que ancla, la que fija límites a esta deriva interpretativa, excluye interpretaciones, marca un punto duro al cual necesitan atenerse los relatos. En resumen, no es la imagen por sí sola la que se nos impone, sino que son los relatos que sobre ella construimos los que movilizan nuestras creencias. La imagen hace hablar y alimenta, desde un punto particular, la producción incesante de la creencia o, en otras palabras, la red semiótica infinita en la cual estamos inmersos. 
Nuestra cultura se basa en la generación de relatos, y es gracias al relato que funcionamos como sociedad. Por eso, desechando cualquier idea categórica de Verdad con mayúsculas, podemos afirmar que la verdad está en todos lados, del mismo modo que el sentido está en todos lados, como plantea Verón. La verdad, que es otro modo de decir "la realidad", es constantemente producida por nosotros en el marco de la red semiótica, a través de relatos que buscan imponerse unos sobre otros. Entre ellos, la imagen se yergue como la garantía, ya no de la existencia de algo, sino de que nuestros relatos poseen un anclaje en algo, y adquieren así un plus de aceptación que les otorga, al menos hasta nuevo aviso, la consideración de "ser verdaderos".

\section{Bibliografía}

Batchen, G. (2004). Arder en deseos. La concepción de la fotografía. Barcelona: Gustavo Gili.

Barthes, R. (1974). “El mensaje fotográfico" y "Retórica de la imagen” en AA.VV. La Semiología. Serie Comunicaciones. Buenos Aires: Tiempo Contemporáneo. . (1989). La cámara lúcida. Nota sobre la fotografía. Barcelona: Paidós.

Dalmasso, M. T. (1994). ¿Qué imagen? ¿De qué mundo? Córdoba: Dirección General de Publicaciones. Universidad Nacional de Córdoba.

Deledalle, G. (1996). Leer a Peirce hoy. Barcelona: Gedisa.

Dubois, P. (1986). El acto fotográfico. De la representación a la recepción. Barcelona: Paidós.

Eco, U. (1982). “Semiología de los mensajes visuales" (1968) en AA.VV. Análisis de las imágenes. Serie Comunicaciones. Barcelona: Ediciones Buenos Aires.

Foucault, M. (1987). El orden del discurso. Barcelona: Tusquets.

Ong, W. J. (1996). Oralidad y escritura. Buenos Aires: FCE.

Peirce, Ch. (1931). Collected Papers. Vol. I. Principles of Philosophy. Cambridge: Harvard University Press. (1932). Collected Papers. Vol. II. Elements of Logic. Cambridge: Harvard University Press. (1987). Obra lógico-semiótica. Madrid: Taurus. (1988). El hombre, un signo (El pragmatismo de Peirce). Barcelona: Crítica.

Ruiz, S. y Triquell, X. (junio 2010). “El estatuto semiótico de las imágenes”. Pensares revista del CIFFyH, 6, 137148.

Verón, E. (noviembre 1978) “Discurso del poder, poder del discurso". En Anais do primero coloquio de Semiótica, Loyola e Pontificia Universidade Católica do Rio de Janeiro, 85-97. 
Abstract:

It is well known the trajectory proposed by Philippe Dubois of Peirce's second trichotomy -icon, index and symbol- to analyze the relationship that have historically been established between photography and "reality": the image as an icon ("mirror" of the world); the image as a symbol (subjected to conventions); the image as an index ("trace" of reality). It is evident that this sequence does not propose a progression but, rather, a possible reading of the visual sign. As a result, icon, index, and symbol, far from referring to a type, constitute ways in which these signs function or are read. However, an inescapable fact is that, from the point of view of reception, in comparison with spoken o written language, images propose a less mediated relationship with a "real" referent and therefore -this is our hypothesis- possess greater efficiency in the fight for the imposition of meanings. Thus, if discourses in general "build reality", visual representations assume within these a particular efficiency so far as they confront us with the strength of evidence (the exact copy or footprint of the real).

Key words:

images - linguistic signs - visual signs - visual semiotics.

Resumo:

Conhecemos o ponto de partida a teoria de Philippe Dubois acerca da segunda tricotomia peirceana -ícone, índice e símbolo- utilizada na análise das posições que, historicamente, foram estabelecidas entre a fotografia e o "real": a imagem ícone ("espelho" do mundo); a imagem símbolo (sujeita a convenções); a imagem índice (vestígio do real). Fica evidente que esta sucessão não propõe uma evolução, mas sim leituras possíveis do signo visual.

Como resultado disto, ícone, índice e símbolo, longe de referir-se a uma tipologia, constituem formas de funcionamento -leituras- de si. No entanto, é inevitável ver que, desde o ponto de vista da recepção, as imagens indicam uma relação menos mediada que o fator linguístico com um suposto referente "real" e, portanto -esta é a nossa hipótese- possuem maior eficácia na luta pela imposição dos sentidos. Junto a esta capacidade, sustentamos que em grande medida o poder diferencial das imagens contra a escrita reside na sua capacidade de gerar histórias e alimentar, dessa maneira, a rede semiótica na qual estamos imersos.

Palavras chave:

imagens - signos linguísticos - signos visuais - semiótica visual.

Imágenes y palabras en la lucha por imposición de sentidos: la imagen como generadora de relatos fue publicado de la página 143 a página154 en Cuadernos del Centro de Estudios de Diseño y Comunicación № 61 